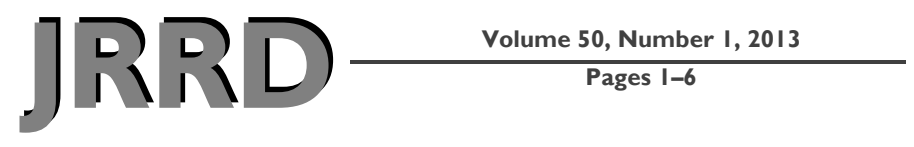

\title{
Report of traumatic brain injury information sources among OIF/OEF Veterans undergoing polytrauma evaluations
}

\author{
Robert J. Spencer, PhD; ${ }^{1}$ Adam P. McGuire; ${ }^{1}$ Heather A. Tree, PhD; ${ }^{1}$ Brigid Waldron-Perrine, PhD; ${ }^{1-2}$ \\ Percival H. Pangilinan, MD; ${ }^{3}$ Linas A. Bieliauskas, PhD $^{1-2^{*}}$ \\ ${ }^{1}$ Department of Mental Health Services, Department of Veterans Affairs (VA) Ann Arbor Healthcare System, Ann \\ Arbor, MI; ${ }^{2}$ Department of Psychiatry, University of Michigan Health System, Ann Arbor, MI; ${ }^{3}$ Department of Physical \\ Medicine and Rehabilitation, VA Ann Arbor Healthcare System, Ann Arbor, MI; and Department of Physical Medicine \\ and Rehabilitation, University of Michigan Health System, Ann Arbor, MI
}

\begin{abstract}
Servicemembers returning from recent conflicts frequently report symptoms associated with traumatic brain injury (TBI) and are subsequently assessed within the Department of Veterans Affairs (VA) medical system. Information on potential cognitive and behavioral correlates of TBI is available from multiple sources. A Veteran's symptom presentation may be significantly influenced by the information he or she has received. Despite knowledge of the relationship between information source and symptom presentation, little work has focused on a characterization of where Veterans receive their information. The present study aims to fill this gap in the literature. We asked 152 Veterans who screened positive for possible TBI within the VA healthcare system about the sources of information they have encountered regarding TBI and its sequelae. "Friends in the military" was the most frequently cited source of information, followed by the Internet, medical professionals, and informational pamphlets. The results of this survey indicate that Veterans are being exposed to information about TBI prior to a formal evaluation and that this information comes from multiple sources of varying reliability. Future research should focus on evaluating and ultimately improving the reliability of this information in order to positively influence the treatment of Veterans.
\end{abstract}

Key words: behavior, information, military, rehabilitation, sequelae, symptoms, TBI, traumatic brain injury, VA, Veterans.

\section{INTRODUCTION}

Traumatic brain injury (TBI) is often reported among servicemembers [1]. Particularly in recent years, information about TBI and its potential aftereffects is readily available through various outlets, including television news features, informational brochures, encounters with medical professionals, and textbook chapters. These sources vary with respect to their availability, cost, trustworthiness, ability to be easily understood, and potential to reach patients. Importantly, knowledge regarding where Veterans get information about TBI may not only potentially influence how Veterans perceive TBI and their subsequent behaviors but may also alter how medical professionals and Veterans communicate.

Informational material appears to affect expectations of the quantity and severity of symptoms that follow head injuries. Tree et al. had undergraduate participants read a brief scenario depicting a mild head injury and then

\footnotetext{
Abbreviations: $\mathrm{TBI}=$ traumatic brain injury, VA $=$ Department of Veterans Affairs.

*Address all correspondence to Linas A. Bieliauskas, PhD; 2101 Commonwealth Blvd, Ste C, Ann Arbor, MI 48105; 734-936-6619; fax: 734-936-9262. Email: linas@umich.edu http://dx.doi.org/10.1682/JRRD.2012.01.0018
} 
report on the number and severity of symptoms they expected would follow [2]. Participants were randomized to receive informational pamphlets that were either disability-focused or recovery-focused. Participants with pamphlets that set an expectation for optimal recovery reported that they expected fewer and less severe head injury symptoms than did the other participants.

Research has also demonstrated that patients' beliefs about head injury symptoms affect their clinical presentation. Simply calling attention to an individual's remote history of concussion can produce measurable declines in neuropsychological test performances [3-4]. Alternately, other investigations have demonstrated that positive expectations based on proper information can result in measurable benefit to patients (i.e., greater recovery from symptoms). If phrased properly, information intervention can have powerful positive effects on outcome. For example, by distributing brief written educational materials following head injuries, Mittenberg et al. found that providing patients with realistic and optimistic information on the trajectory of recovery from brain injury resulted in improved cognitive and physical functioning [5-6]. Thus, it is of obvious importance to disseminate accurate information to individuals, including Veterans, suspected of having sustained any type of head injury.

The present study surveyed exposure to various sources of information about head injuries among Veterans being evaluated for possible TBI prior to a formal TBI assessment. Knowledge of the resources utilized by these individuals will allow for accurate information to be disseminated in appropriate and effective ways to such persons, positively influencing recovery and instilling hope.

\section{METHODS}

\section{Participants}

This study examined data from 152 Veterans, all of whom screened positive for possible head injury on the standard Department of Veterans Affairs (VA) clinical reminder. This screen is given to all returning Operation Iraqi Freedom/Operation Enduring Freedom Veterans and consists of asking the Veterans about their experience with postconcussive symptoms. The Veterans in this study were consecutive referrals made on the basis of this screen and seen in the TBI clinic at a Midwestern VA hospital for a comprehensive medical examination. Although the surveys were not linked to identifying patient data for this study, the sample is drawn from the same clinic as Spencer et al. [7]; therefore, the demographic data are probably quite similar.

\section{Materials and Procedures}

Prior to their comprehensive TBI assessment, Veterans completed a survey asking which sources they have used to learn more about TBI. We sought such information to establish what assumptions Veterans may have had about their possible head injuries. The survey (items presented in the Table) included common sources of information about TBI. Patients indicated which sources they had consulted, checking all that applied. Veterans completed the survey in the clinic prior to their appointments.

\section{RESULTS}

The Table presents the results of the survey in descriptive statistics. Friends in the military (55 [36.2\%]) were the most consulted source of information, followed by the Internet (49 [32.2\%]) and medical professionals not affiliated with a TBI clinic (48 [31.6\%]). Four Veterans reported consulting sources not listed on the survey, which included the library and general VA resources. Overall, 140 (92.1\%) Veterans consulted at least one source, 86 (56.6\%) consulted at least two, and 51 (33.6\%) consulted at least three. Of the Veterans, 52 (34.2\%) used at least one pamphlet; 44 (28.9\%) used a military pamphlet, and 14 (9.2\%) used a civilian pamphlet.

Table.

Frequency with which various informational sources are consulted by Veterans $(n=152)$ undergoing evaluation for possible traumatic brain injury (TBI).

\begin{tabular}{lc}
\hline \multicolumn{1}{c}{ Information Source } & $\begin{array}{c}\text { Veteran, } \\
\boldsymbol{n}(\mathbf{\%})\end{array}$ \\
\hline Friend in Military (fellow servicemember or Marine) & $55(36.2)$ \\
Internet & $49(32.2)$ \\
Medical Professional Not Affiliated with TBI Clinic & $48(31.6)$ \\
Military Pamphlet & $44(28.9)$ \\
Member of TBI Clinic & $36(23.7)$ \\
Civilian Friend and/or Family Member & $27(17.8)$ \\
Magazine & $22(14.5)$ \\
Civilian Pamphlet & $14(9.2)$ \\
Textbook or Formal Coursework & $14(9.2)$ \\
Television & $12(7.9)$ \\
Superior Officer & $10(6.6)$ \\
Other & $4(2.6)$ \\
\hline \hline
\end{tabular}




\section{DISCUSSION}

Results from this survey indicate that most Veterans are exposed to information about TBI prior to their formal TBI evaluation; however, we did not examine the quality and content of this information. Nearly one in four participants reported learning about TBI from members of the TBI clinic prior to their evaluation. These contacts were usually brief; consisted mainly of discussions regarding the evaluation; and took place during TBI screening, case management, or interactions with TBI clinic personnel working in other clinics. Relatively few participants consulted medical textbooks and most used word of mouth, but more than one in three participants were exposed to literature in pamphlet form. This indicates that, unlike word of mouth, which can be dubious and more difficult to manage, properly constructed pamphlets are a promising method for reaching potential patients and disseminating accurate information about head injuries. Internet Web sites and informational pamphlets can vary widely in terms of credibility. This exposure to information likely influences the Veteran's expectations for his or her own experience with symptom recovery, and prior research indicates that these expectations could affect symptom expression and alter the Veteran's interpretation of his or her subjective experience and behavior [3].

The expectation of postconcussive symptoms may lead to the experience of postconcussive symptoms [8]. Individuals reporting postdeployment problems understandably seek explanations for their symptoms. Research has demonstrated that individuals with head injuries are at increased risk of misattributing common problems and symptoms, such as forgetting car keys and having headaches, as sequelae of a head injury [5]. Furthermore, people tend to fail to recall the frequency with which they had such problems prior to the head injury, making current functioning seem worse by comparison [9]. Providing responsible information to Veterans and their families is therefore important for reducing faulty attributions and unnecessary adaptation of a sick role.

The current findings warrant optimism that pamphlets might be used in intervention studies. Mittenberg et al. found good results giving educational materials to patients in emergency rooms, but it remains to be seen whether educational interventions have a similarly positive effect on those with more remote injuries, such as those seen within the VA system [5-6]. The current study found that nearly one in three Veterans gained information about head injuries from medical professionals, such as primary care physicians, nurses, and social workers who were not directly involved with the TBI clinic. Wade et al. found that outpatient medical follow-ups of individuals with head injury lead to better functional outcomes [10]. Given the potentially beneficial effects of providing accurate information, a strong argument can be made for providing written and verbal information to Veterans as soon as possible after head injury or the initial TBI screening. At the least, providers in polytrauma clinics should engage Veterans in discussions that engender hope and the expectation of improved functionality.

Educational interventions have strong promise in providing Veterans and servicemembers with the foundations for recovery. However, widely distributed educational campaigns can also lead to dissemination of information that can be used for financial benefit. There is a high rate of symptom exaggeration and fabrication among individuals evaluated for head injury within the VA [11]. Although several methods exist for detecting dissimulation, perhaps no method can yield complete accuracy. Because the VA provides financial compensation based on disability, there is a risk that disseminating education can lead to a more refined symptom exaggeration. Despite this risk, it is more likely that the benefits of educational interventions outweigh the risks.

\section{LIMITATIONS AND FUTURE DIRECTIONS}

The limitations of the present study can likely be successfully addressed via additional research. Although we now know which sources are reaching our Veteran patients, we have no information on the beliefs of the Veterans regarding the veracity of the information. Perhaps few people consult medical reference literature, but those who do likely take the information at face value. Alternatively, word of mouth transmission might be common but of limited influence because of lack of credibility. Additional survey research can address the issue of how patients regard the credibility of various sources. Knowing this information would let clinicians working with patients or those conducting large-scale educational campaigns know which sources are likely to be embraced by Veterans or servicemembers.

The current study examined survey data in isolation. Future work could examine whether providing timely 
and accurate information can lead to better functional outcomes for Veterans and servicemembers. Suhr and Gunstad found that calling attention to a history of head injury leads to measurable decline on neuropsychological testing [3-4]. It stands to reason, then, that providing an expectation for recovery might have positive effects on rehabilitation. Research within the VA can explore whether beneficial effects exist in polytrauma clinics among individuals provided with this information, then assess the effects immediately and at follow-up.

Another limitation to this study concerns the sample used. The current survey was of Veterans who reported some head injury symptoms during a routine clinical screening at a VA medical facility. This sample might be qualitatively different than either the population of Veterans at large or Veterans who experienced head injuries with few lingering effects.

\section{CONCLUSIONS}

Veterans consult a variety of sources to learn about head injuries. Knowledge of the sources they consult can guide educational interventions.

\section{ACKNOWLEDGMENTS}

\section{Author Contributions:}

Study concept and design: R. J. Spencer, H. A. Tree.

Acquisition of data: R. J. Spencer, A. P. McGuire, H. A. Tree,

P. H. Pangilinan.

Analysis and interpretation of data: R. J. Spencer, A. P. McGuire, B. Waldron-Perrine.

Drafting of manuscript: R. J. Spencer, L. A. Bieliauskas, B. WaldronPerrine, P. H. Pangilinan.

Critical revision of manuscript for important intellectual content:

R. J. Spencer, L. A. Bieliauskas, H. A. Tree, B. Waldron-Perrine.

Statistical analysis: R. J. Spencer.

Administrative, technical, and material support: R. J. Spencer,

A. P. McGuire, B. Waldron-Perrine.

Study supervision: L. A. Bieliauskas, P. H. Pangilinan.

Financial Disclosures: The authors have declared that no competing interests exist.

Funding/Support: This study was unfunded at the time of manuscript preparation.

Additional Contributions: Dr. Tree is now with the North Florida/ South Georgia Veterans Health System, Gainesville, Florida; Mr. McGuire is now with the Seattle Pacific University, Seattle, Washington; and Dr. Waldron-Perrine is now with the Rehabilitation Institute of Michigan, Detroit Medical Center, Detroit, Michigan, and the
Department of Physical Medicine and Rehabilitation, Wayne State University School of Medicine, Detroit, Michigan.

Institutional Review: Because no identifying information was collected, the institutional review board deemed this study exempt from formal review.

Participant Follow-Up: The authors do not plan to notify participants of the publication of this study because of a lack of contact information.

\section{REFERENCES}

1. Belanger HG, Uomoto JM, Vanderploeg RD. The Veterans Health Administration's (VHA's) Polytrauma System of Care for mild traumatic brain injury: costs, benefits, and controversies. J Head Trauma Rehabil. 2009;24(1):4-13. [PMID:19158591] http://dx.doi.org/10.1097/HTR.0b013e3181957032

2. Tree HA, Spencer RJ, Pangillinan P, Suhr JA, Bieliauskas LA. Informational literature influences symptom expectation following head injury: An analog study. 39th Annual Meeting of the International Neuropsychological Society; 2011 Feb 2-5; Boston, MA.

3. Suhr JA, Gunstad J. "Diagnosis Threat”: the effect of negative expectations on cognitive performance in head injury. J Clin Exp Neuropsychol. 2002;24(4):448-57. [PMID:12187458] http://dx.doi.org/10.1076/jcen.24.4.448.1039

4. Suhr JA, Gunstad J. Further exploration of the effect of "diagnosis threat" on cognitive performance in individuals with mild head injury. J Int Neuropsychol Soc. 2005;11(1): 23-29. [PMID:15686605] http://dx.doi.org/10.1017/S1355617705050010

5. Mittenberg W, DiGiulio DV, Perrin S, Bass AE. Symptoms following mild head injury: expectation as aetiology. J Neurol Neurosurg Psychiatry. 1992;55(3):200-204. [PMID:1564481] http://dx.doi.org/10.1136/jnnp.55.3.200

6. Mittenberg W, Canyock EM, Condit D, Patton C. Treatment of post-concussion syndrome following mild head injury. J Clin Exp Neuropsychol. 2001;23(6):829-36. [PMID:11910547] http://dx.doi.org/10.1076/jcen.23.6.829.1022

7. Spencer RJ, Drag LL, Walker SJ, Bieliauskas LA. Selfreported cognitive symptoms following mild traumatic brain injury are poorly associated with neuropsychological performance in OIF/OEF veterans. J Rehabil Res Dev. 2010;47(6):521-30. [PMID:20848365] http://dx.doi.org/10.1682/JRRD.2009.11.0181

8. Iverson GL, Zasler ND, Lange RT. Post-concussive disorder. In: Zasler ND, Katz DI, Zafonte RD, editors. Brain injury medicine: Principles and practice. New York (NY): Demos Medical Publishing; 2007. p. 373-405. 
9. Gunstad J, Suhr JA. "Expectation as etiology” versus "the good old days": postconcussion syndrome symptom reporting in athletes, headache sufferers, and depressed individuals. J Int Neuropsychol Soc. 2001;7(3):323-33.

[PMID:11311033]

http://dx.doi.org/10.1017/S1355617701733061

10. Wade DT, Crawford S, Wenden FJ, King NS, Moss NE. Does routine follow up after head injury help? A randomised controlled trial. J Neurol Neurosurg Psychiatry. 1997;62(5):478-84. [PMID:9153604]

http://dx.doi.org/10.1136/jnnp.62.5.478

11. Armistead-Jehle P. Symptom validity test performance in U.S. veterans referred for evaluation of mild TBI. Appl Neuropsychol. 2010;17(1):52-59. [PMID:20146122] http://dx.doi.org/10.1080/09084280903526182
Submitted for publication January 27, 2012. Accepted in revised form May 2, 2012.

This article and any supplementary material should be cited as follows:

Spencer RJ, McGuire AP, Tree HA, Waldron-Perrine B, Pangilinan PH, Bieliauskas LA. Report of traumatic brain injury information sources among OIF/OEF Veterans undergoing polytrauma evaluations. J Rehabil Res Dev. 2013;50(1):1-6.

http://dx.doi.org/10.1682/JRRD.2012.01.0018

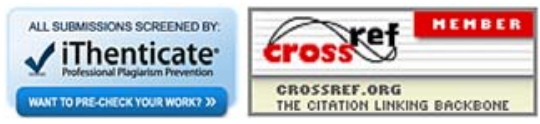


